\title{
High-entropy Rare-earth Zirconate Ceramics With Low Thermal Conductivity for Advanced Thermal Barrier Coatings
}

\section{Baosehng Xu ( $\nabla$ xubsh@bit.edu.cn)}

Beijing Institute of Technology

\section{Debao LIU}

Beijing Institute of Technology

\section{Baolu SHI}

Beijing Institute of Technology

\section{Liyan GENG}

Shanghai Institute of Space Power-Sources

\section{Yiguang WANG}

Beijing Institute of Technology

\section{Baosheng XU}

Beijing Institute of Technology

\section{Yanfei Chen}

Beijing Institute of Technology

\section{Research Article}

Keywords: High-entropy rare-earth zirconates, First-principles calculations, Thermal conductivity, Young's modulus, Thermal barrier coatings

Posted Date: November 29th, 2021

DOI: https://doi.org/10.21203/rs.3.rs-1098359/v1

License: (c) (1) This work is licensed under a Creative Commons Attribution 4.0 International License. Read Full License 
High-entropy rare-earth zirconate ceramics with Low Thermal conductivity for advanced thermal barrier coatings

Debao LIU ${ }^{1}$, Baolu SHI ${ }^{1}$, Liyan GENG ${ }^{2}$, Yiguang WANG ${ }^{1}$, Baosheng $\mathrm{XU}^{*}, 1$ and Yanfei $\mathrm{CHEN}^{* *}, 1$

${ }^{1}$ Institute of Advanced Structure Technology, Beijing Institute of Technology, Beijing 100081, P. R. China

${ }^{2}$ Shanghai Space Propulsion Technology Research Institute, Shanghai, 201109, P. R. China

Abstract: In this work, we have successfully fabricated a novel high-entropy rare-earth zirconate $\left(\mathrm{La}_{0.2} \mathrm{Nd}_{0.2} \mathrm{Sm}_{0.2} \mathrm{Gd}_{0.2} \mathrm{Yb}_{0.2}\right)_{2} \mathrm{Zr}_{2} \mathrm{O}_{7}$ $\left(5 \mathrm{RE}_{2} \mathrm{Zr}_{2} \mathrm{O}_{7}\right)$ ceramics and its counterparts by using a new high-speed grinding strategy combined with typical solid-state reaction method. The X-ray diffraction (XRD) and Raman spectroscopy analysis indicated that the as-prepared $5 \mathrm{RE}_{2} \mathrm{Zr}_{2} \mathrm{O}_{7}$ ceramics performed single-phase defect fluorite-type structures with highly sintering resistant and excellent thermal stability. The possibility of formation of $5 \mathrm{RE}_{2} \mathrm{Zr}_{2} \mathrm{O}_{7}$ was verified via first-principles calculations. Meanwhile, the phase structure, thermophysical and mechanical properties of the samples were systematically investigated. The results showed that the $5 \mathrm{RE}_{2} \mathrm{Zr}_{2} \mathrm{O}_{7}$ ceramics demonstrated lower thermal conductivity $\left(0.9-1.72 \mathrm{~W} \cdot \mathrm{m}^{-1} \cdot \mathrm{K}^{-1}\right)$ and higher thermal expansion coefficients $\left(10.9 \times 10^{-6} \mathrm{~K}^{-1}\right.$ at $\left.1273 \mathrm{~K}\right)$ than its counterparts. Furthermore, the $5 \mathrm{RE}_{2} \mathrm{Zr}_{2} \mathrm{O}_{7}$ ceramics presented

\footnotetext{
* Corresponding authors.
}

E-mail: xubsh@bit.edu.cn; chenyf@bit.edu.cn 
outstanding mechanical properties including large Young's modulus (186-257 GPa), higher fracture toughness and lower brittleness index than that of YSZ. Therefore, in view of various excellent properties, the as-prepared $5 \mathrm{RE}_{2} \mathrm{Zr}_{2} \mathrm{O}_{7}$ ceramics possess great potential for applications in the field of thermal barrier coatings.

Keywords: High-entropy rare-earth zirconates; First-principles calculations; Thermal conductivity; Young's modulus; Thermal barrier coatings

\section{Introduction}

Thermal barrier coatings (TBCs), as refractory ceramic materials, are widely used in aircraft engines and industrial gas turbines to protect their metallic components against high temperatures during operation, which can extend the life-span of metallic components and energy efficiency at elevated operation temperatures [1-4]. Generally speaking, the state-of-the-art TBCs have some important merits, such as high melting point, low thermal conductivity, high chemical stability, ideal sintering resistance with no phase transformation at elevated temperature, enhanced mechanical properties, and matched thermal expansion coefficients (CTEs) with the metallic substrate, etc $[5,6]$. In the past decades, the study of TBC materials has received enormous development and some representative TBCs, such as 6-8 wt. $\% \mathrm{Y}_{2} \mathrm{O}_{3}$-stabilized $\mathrm{ZrO}_{2}$ (YSZ) [7], $\mathrm{Yb}_{3} \mathrm{Al}_{5} \mathrm{O}_{12}$ [8] and mullite [9] have been extensively studied. 
Among these materials, the YSZ has captured people's eyes and become a typical TBCs ceramic material because of its low thermal conductivity and high thermal expansion coefficient [7]. Unfortunately, the formation of cubic and tetragonal phase will result in volumetric expansion and spallation when the operation temperature beyond $1473 \mathrm{~K}$, which lead to the failure of YSZ TBCs.

Nowadays, great efforts have been made to investigate several kinds of new promising TBCs candidates at higher operation temperatures, such as $\mathrm{RE}_{2} \mathrm{Zr}_{2} \mathrm{O}_{7}$ (rare-earth zirconates, $\mathrm{RE}$ : rare earth element) [10], $\mathrm{REPO}_{4}$ [11] and $\mathrm{RE}_{2} \mathrm{Al}_{4} \mathrm{O}_{9}$ [12]. Among these new TBCs candidates, the pyrochlore or fluorite structured $\mathrm{RE}_{2} \mathrm{Zr}_{2} \mathrm{O}_{7}$ present some excellent performances, such as lower thermal conductivity and high CTEs value, high phase stability and lower oxygen ion diffusivity than that of present used YSZ [13-15], making them very important promising TBCs. However, the $\mathrm{RE}_{2} \mathrm{Zr}_{2} \mathrm{O}_{7}$ usually perform poor durability and relatively low CTEs, which hinders its practical applications as TBCs [16-18].

In order to break through this technical bottleneck to improve the overall performances. The $\mathrm{RE}_{2} \mathrm{Zr}_{2} \mathrm{O}_{7}$ has been investigated by doping methods with different kinds of rare earth elements [19]. Very recently, the high-entropy ceramics (HECs), as a single-phase solid solution with multi-principal elements, have attracted increasing attentions because of some intriguing properties, for example, lower thermal conductivity, 
super mechanical properties, improved chemical stability and oxidation resistance than those of the its single counterparts [20]. As research study suggests, the overall performances of the HECs can be effected by four aspects, including severe lattice distortion, high-entropy, sluggish diffusion and cocktail effects [21]. Zhao et al. [22] fabricated $\left(\mathrm{La}_{0.2} \mathrm{Ce}_{0.2} \mathrm{Nd}_{0.2} \mathrm{Sm}_{0.2} \mathrm{Eu}_{0.2}\right)_{2} \mathrm{Zr}_{2} \mathrm{O}_{7} \mathrm{HECs}$, which exhibited sluggish grain growth and ultra-low thermal conductivity $\left(0.76 \mathrm{~W} \cdot \mathrm{m}^{-1} \cdot \mathrm{K}^{-1}\right)$ at room temperature. Ren et al. [13] prepared $\left(\mathrm{Sm}_{0.2} \mathrm{Eu}_{0.2} \mathrm{~Tb}_{0.2} \mathrm{Dy}_{0.2} \mathrm{Lu}_{0.2}\right)_{2} \mathrm{Zr}_{2} \mathrm{O}_{7}$ HECs with defective fluorite structure, which perform much lower thermal conductivity $\left(0.86 \mathrm{~W} \cdot \mathrm{m}^{-1} \cdot \mathrm{K}^{-1}, 1273 \mathrm{~K}\right)$ compared with its counterparts. Through atmospheric plasma spraying method, Zhou et al. [23] systhesized $\left(\mathrm{La}_{0.2} \mathrm{Nd}_{0.2} \mathrm{Sm}_{0.2} \mathrm{Eu}_{0.2} \mathrm{Gd}_{0.2}\right)_{2} \mathrm{Zr}_{2} \mathrm{O}_{7} \mathrm{HECs}$. The as-prepared samples showed excellent thermal stability compared with $\mathrm{La}_{2} \mathrm{Zr}_{2} \mathrm{O}_{7}$. $\mathrm{Li}$ et al. [24] produced high-entropy pyrochlore $\left(5 \mathrm{RE}_{1 / 5}\right)_{2} \mathrm{Zr}_{2} \mathrm{O}_{7}$, which performed low thermal conductivities below $1 \mathrm{~W} \cdot \mathrm{m}^{-1} \cdot \mathrm{K}^{-1}$ in the temperature range of 573-1473 K. However, to the best of our knowledge, most researches are fixed on studying several experimental properties or theoretical calculations other than systematically combining the theoretical calculation and experimental multi-property analysis of $\mathrm{RE}_{2} \mathrm{Zr}_{2} \mathrm{O}_{7} \mathrm{HECs}$. Moreover, the particle size of $\mathrm{RE}_{2} \mathrm{Zr}_{2} \mathrm{O}_{7} \mathrm{HECs}$ reported are usually in the micron scale.

Inspired by the HECs concept, in this work, we have successfully 
synthesized a novel single phase high-entropy rare-earth zirconate $\left(\mathrm{La}_{0.2} \mathrm{Nd}_{0.2} \mathrm{Sm}_{0.2} \mathrm{Gd}_{0.2} \mathrm{Yb}_{0.2}\right)_{2} \mathrm{Zr}_{2} \mathrm{O}_{7}\left(5 \mathrm{RE}_{2} \mathrm{Zr}_{2} \mathrm{O}_{7}\right)$ ceramics by using a new high-speed grinding strategy combining with a typical solid-state reaction method, and the medium-entropy rare-earth as well as single rare-earth counterparts were also prepared by the same method. The first-principles calculations based on density functional theory (DFT) was employed to prove the possible formation of $5 \mathrm{RE}_{2} \mathrm{Zr}_{2} \mathrm{O}_{7}$. The microstructure, composition, thermophysical properties and mechanical performances of these obtained samples have been systematically investigated. This work points out a novel strategy and offers great value for designing of next generation TBCs with unique properties.

\section{Experimental and calculation procedures}

\subsection{Materials}

Commercially available $\mathrm{La}_{2} \mathrm{O}_{3}, \quad \mathrm{Nd}_{2} \mathrm{O}_{3}, \quad \mathrm{Sm}_{2} \mathrm{O}_{3}, \mathrm{Gd}_{2} \mathrm{O}_{3}$ and $\mathrm{Yb}_{2} \mathrm{O}_{3}$ (particle size D50 $=5 \mu \mathrm{m}$, purity $\geq 99.99 \%$ ) were purchased from Shanghai Diyang Co., Shanghai, China. The monoclinic $\mathrm{ZrO}_{2}$ (particle size D50 $=0.2 \mu \mathrm{m}$, purity $\geq 99.99 \%$ ) was purchased from Sinopharm Chemical Reagent Co., Shanghai, China. The above reagents were used as starting materials and were used as received.

\subsection{Preparation of the samples}

The raw materials were stoichiometrically weighed and ball-milled $\left(\mathrm{ZrO}_{2}\right.$ 
ball, $\Phi=2 \mathrm{~mm}$ ) using vertical mixing ball-milling equipment (Union Process, 01-HD, American) with ethanol as the medium for $3 \mathrm{~h}$ at 600 $\mathrm{r} / \mathrm{min}$. The mixed powders were dried at $363 \mathrm{~K}$ for $24 \mathrm{~h}$ and sifted employing a 200-mesh sieve before granulation and then sifted through a 80-mesh sieve. After that, the ground powder mixtures were condensed into sheets $(\Phi=30 \mathrm{~mm})$ at a uniaxial pressure of $25 \mathrm{MPa}$ for $3 \mathrm{~min}$ and then cold isostatic pressed under $200 \mathrm{MPa}$ for $2 \mathrm{~min}$. The obtained pressed disks were calcined at $873 \mathrm{~K}$ for $3 \mathrm{~h}\left(1{ }^{\circ} \mathrm{C} / \mathrm{min}\right)$ to burn out the PVA binders and then at $1773 \mathrm{~K}$ for $3 \mathrm{~h}\left(2{ }^{\circ} \mathrm{C} / \mathrm{min}\right)$ in air. Reference single rare-earth zirconate $\mathrm{RE}_{2} \mathrm{Zr}_{2} \mathrm{O}_{7}\left(\mathrm{La}_{2} \mathrm{Zr}_{2} \mathrm{O}_{7}\right.$ or $\left.\mathrm{Yb}_{2} \mathrm{Zr}_{2} \mathrm{O}_{7}\right)$ ceramics and medium-entropy rare-earth zirconate $3 \mathrm{RE}_{2} \mathrm{Zr}_{2} \mathrm{O}_{7}$ $\left(\left(\mathrm{La}_{1 / 3} \mathrm{Sm}_{1 / 3} \mathrm{Yb}_{1 / 3}\right)_{2} \mathrm{Zr}_{2} \mathrm{O}_{7}\right)$ ceramics were also prepared under the same conditions.

\subsection{Structure characterization methods}

A field emission scanning electron microscope (SEM, FEIQuanta 600) equipped with energy dispersive spectroscopy (EDS, Oxford INCAxsight 6427) was applied to observe the morphology and elemental distributions of the samples. Transmission electron microscopy (TEM, JEOL 2010 F, Japan) with selected-area electron diffraction (SAED) was conducted to analyse the morphological characteristics and crystalline structure of the obtained samples. The phase characterization of samples were identified by X-ray diffraction (XRD, Bruker D8 Advance). The theoretical density 
$\left(\rho_{o}\right)$ and experimental density $(\rho)$ were measured based on the lattice parameter measured by XRD patterns and the Archimedes method, respectively. Thermogravimetric analysis (TGA) and differential scanning calorimetry (DSC) were performed using a thermogravimetric analyser (NETZSCH STA 449F3, Germany). The Raman spectra were obtained on a microscopic confocal Raman spectrometer (Renishaw, RM2000, UK) by using an argon ion laser with radiation at $532 \mathrm{~nm}$. The Fourier transform infrared (FT-IR) spectra were recorded on a WQF-410 spectrophotometer (Beijing Secondary Optical Instruments, China).

\subsection{The first-principles calculations}

We employ the Vienna ab initio simulation package (VASP) by using the Cambridge Serial Total Energy Package (CASTEP) code to perform the first principle calculations based on the DFT [25]. Through first principle calculations, the stoichiometry and mobility of $\mathrm{RE}, \mathrm{Zr}$, and $\mathrm{O}$ atoms in $5 \mathrm{RE}_{2} \mathrm{Zr}_{2} \mathrm{O}_{7}$ were verified. The mixing enthalpy was calculated from a $5 \times 1 \times 1$ supercell with $\mathrm{La}_{4} \mathrm{Nd}_{4} \mathrm{Sm}_{4} \mathrm{Gd}_{4} \mathrm{Yb}_{4} \mathrm{Zr}_{20} \mathrm{O}_{70}$. The generalized gradient approximation (GGA) of Perdew-Burke-Ernzerhof (PBE) was employed to characterize the exchange correlation energy [26]. Under the condition of integrated Brillouin zone, the k-point mesh was divided into $2 \times 1 \times 2$ using the Monkhorst-Pack method.

The mixing enthalpy was defined as the energy relative to five single rare-earth zirconates, according to the following equation: 


$$
\begin{gathered}
\Delta H_{\text {mix }}\left(\mathrm{La}_{4} \mathrm{Nd}_{4} \mathrm{Sm}_{4} \mathrm{Gd}_{4} \mathrm{Yb}_{4} \mathrm{Zr}_{20} \mathrm{O}_{70}\right)= \\
\frac{E_{\text {total }}\left(\mathrm{La}_{4} \mathrm{Nd}_{4} \mathrm{Sm}_{4} \mathrm{Gd}_{4} \mathrm{Yb}_{4} \mathrm{Zr}_{20} \mathrm{O}_{70}\right)-E_{\text {total }}\left(\mathrm{RE}_{8} \mathrm{Zr}_{8} \mathrm{O}_{28}\right)}{110}
\end{gathered}
$$

where $E_{\text {total }}\left(\mathrm{La}_{4} \mathrm{Nd}_{4} \mathrm{Sm}_{4} \mathrm{Gd}_{4} \mathrm{Yb}_{4} \mathrm{Zr}_{20} \mathrm{O}_{70}\right)$ and $E_{\text {total }}\left(\mathrm{RE}_{8} \mathrm{Zr}_{8} \mathrm{O}_{28}\right)$ are the total energy of high-entropy rare-earth zirconates and total energy of single rare-earth zirconates, respectively.

Because of the equal relationship for the rare-earth elements, the ideal mixing entropy of the supercell $\mathrm{La}_{4} \mathrm{Nd}_{4} \mathrm{Sm}_{4} \mathrm{Gd}_{4} \mathrm{Yb}_{4} \mathrm{Zr}_{20} \mathrm{O}_{70}$ was calculated to be as follows [27]:

$$
S_{\text {mix }}=R \ln N
$$

Therefore, the mixing Gibbs free energy can be calculate as follows [28]:

$$
G_{m i x}=H_{m i x}-T S_{m i x}
$$

Obviously, the Gibbs free energy can be reduced (the $5 \mathrm{RE}_{2} \mathrm{Zr}_{2} \mathrm{O}_{7}$ system stabilized) through reducing the $H_{m i x}$ values or increasing the $T S_{m i x}$ values.

\subsection{Thermophysical property measurement}

The thermal conductivity of samples were calculated from the thermal diffusivity $(\lambda)$, specific heat capacity $\left(C_{p}\right)$, and density $(\rho)$ :

$$
\kappa=\lambda \cdot \rho \cdot C_{P}
$$

The $\lambda$ was tested by laser reflection method (NETZSCH, LFA-457, Germany) from ambient temperature to $1273 \mathrm{~K}$, the $C_{p}$ was calculated 
based on the Neumann-Kopp law [29].

The CTEs of the samples $(3 \times 3 \times 10 \mathrm{~mm})$ were measured using a high-temperature dilatometer analyzer (TMA 402 F3, Germany). The as-prepared $5 \mathrm{RE}_{2} \mathrm{Zr}_{2} \mathrm{O}_{7}$ ceramic bulks were heat treated at $1573 \mathrm{~K}$ for $5-40 \mathrm{~h}$ to to evaluate their thermal stability at high temperature.

\subsection{Mechanical performance analysis}

The Vickers hardness of the samples were measured under the force of $0.5 \mathrm{~kg} f$ with a holding time of $10 \mathrm{~s}$ using a Vickers hardness tester (Shanghai Yanrun Optoelectronics Technology, HV-50Z). The Young's modulus were tested through a nanoindenter (Indenter G200). Each specimen was measured 3 times and the average value were taken for accuracy. The value of Vickers hardness was calculated as follows:

$$
\mathrm{H} V=1.854 \frac{F}{d^{2}}
$$

where $F$ and $d$ are the indentation loadlength and indent diagonal, respectively. Therefore, the fracture toughness can be obtained based on the Vickers hardness and Young's modulus $(E)$ :

$$
K_{I C}=0.016\left(\frac{E}{H V}\right)^{1 / 2} \frac{F}{C^{3 / 2}}
$$

where $C$ (half-length of the crack) is the distance from the center of indentation to the tip of the crack.

\section{Results and discussion}

\subsection{Phase stability and structural characterization}


The pyrochlore structure (Fig. 1(a)) belongs to the space group $\mathrm{Fd} \overline{3} \mathrm{~m}$ $(\mathrm{Z}=8)$. In this kind of structure, the $\mathrm{Zr}$ atoms equally occupy the $16 \mathrm{~d}$ site and RE atoms homogeneously occupy the 16c site. Specifically, the $O$ atoms occupy the $8 \mathrm{~b}$ and $48 \mathrm{f}$ sites, while the $\mathrm{O}$ vacancy occupies the $8 \mathrm{a}$ site [30,31]. Meanwhile, the defective fluorite structure (Fig. 1(b)) exhibits the space group of $\mathrm{Fm} \overline{3} \mathrm{~m}(\mathrm{Z}=1)$. The cations and of $\mathrm{O}$ vacancies present disordered distributions [32].
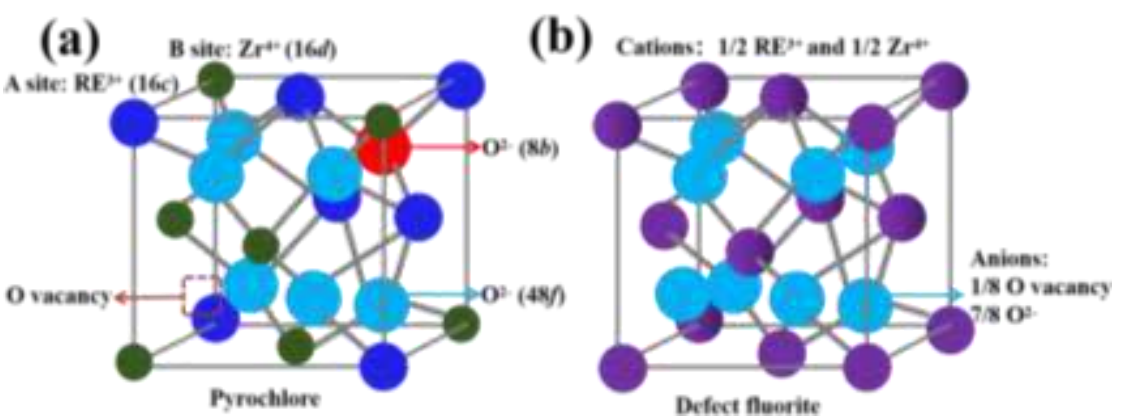

Fig. 1. The schematic diagram of crystal structure of pyrochlore and defective fluorite: (a) 1/8 of unit cell of pyrochlore structure, (b) defective fluorite structure.

The SEM images with corresponding elemental mappings of the sintered samples were shown in Fig. 2. From the EDS elemental mapping results, it can be clearly seen that the $\mathrm{RE}, \mathrm{Zr}$ and $\mathrm{O}$ elements were uniformly distributed in the whole field, indicating that all the samples are chemically homogeneous.

Fig. 3(a) showed the microstructure of the $5 \mathrm{RE}_{2} \mathrm{Zr}_{2} \mathrm{O}_{7}$ ceramic bulk, which present no obvious microvoids on the polished and thermally etched surface. To further verify the elemental distribution and structure information, the TEM and HRTEM technology were employed. As 
depicted in Fig. 3(b), irregular particles (about $210 \mathrm{~nm}$ ) of microscale agglomerate together to form micro-sized particles. The HRTEM (Fig. 3(c)) image showed an lattice spacing of $0.259 \mathrm{~nm}$ which corresponding to the (400) plane [33] and the lattice parameter was calculated to be $10.631 \AA$ (based on the Equation (7)). The lattice parameters calculated from XRD patterns and density of the samples were shown in Table 1. Clearly, the relative density of the samples are in the range between $98.47 \%$ and $98.89 \%$.

$$
d_{h k l}=\frac{a}{\sqrt{h^{2}+k^{2}+l^{2}}}
$$

The SAED pattern along the [0-11] zone axis (Fig. 3(d)) also revealed that the $5 \mathrm{RE}_{2} \mathrm{Zr}_{2} \mathrm{O}_{7}$ had a single defect fluorite structure. All the elements ( $\mathrm{La}, \mathrm{Nd}, \mathrm{Sm}, \mathrm{Gd}, \mathrm{Yb}, \mathrm{Zr}$ and $\mathrm{O}$ ), as was shown in Fig. 3(e), were homogeneously distributed on the microscale without noticeable elemental segregation or clustering.

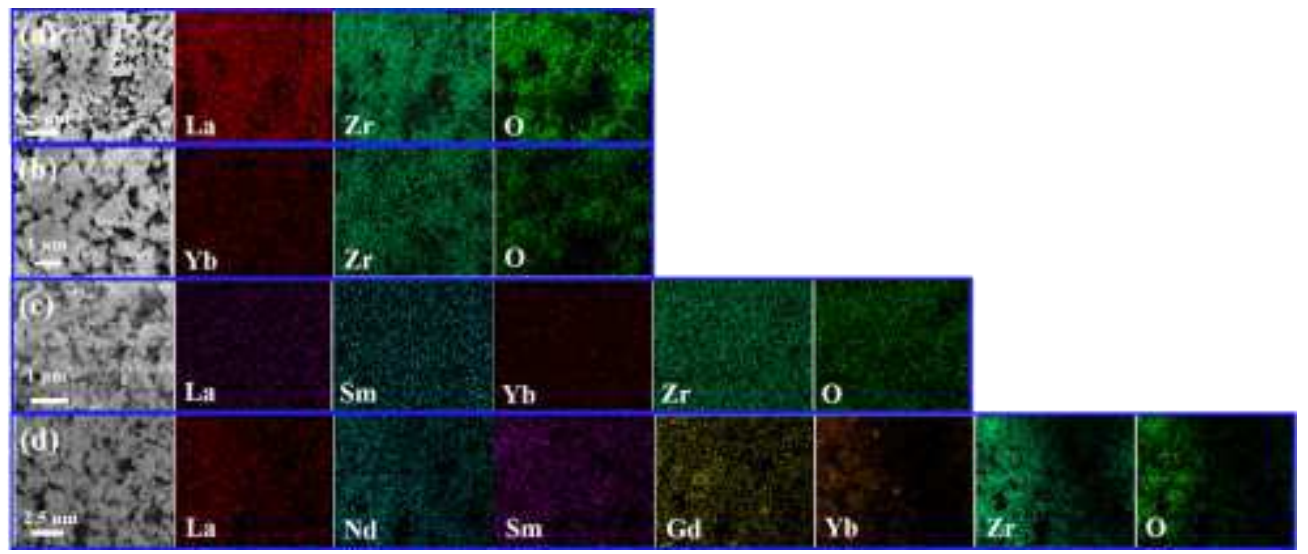

Fig. 2. The SEM images and elemental mappings for: (a) $\mathrm{La}_{2} \mathrm{Zr}_{2} \mathrm{O}_{7}$, (b) $\mathrm{Yb}_{2} \mathrm{Zr}_{2} \mathrm{O}_{7}$, (c) $3 \mathrm{RE}_{2} \mathrm{Zr}_{2} \mathrm{O}_{7}$, and (d) $5 \mathrm{RE}_{2} \mathrm{Zr}_{2} \mathrm{O}_{7}$ powder. 

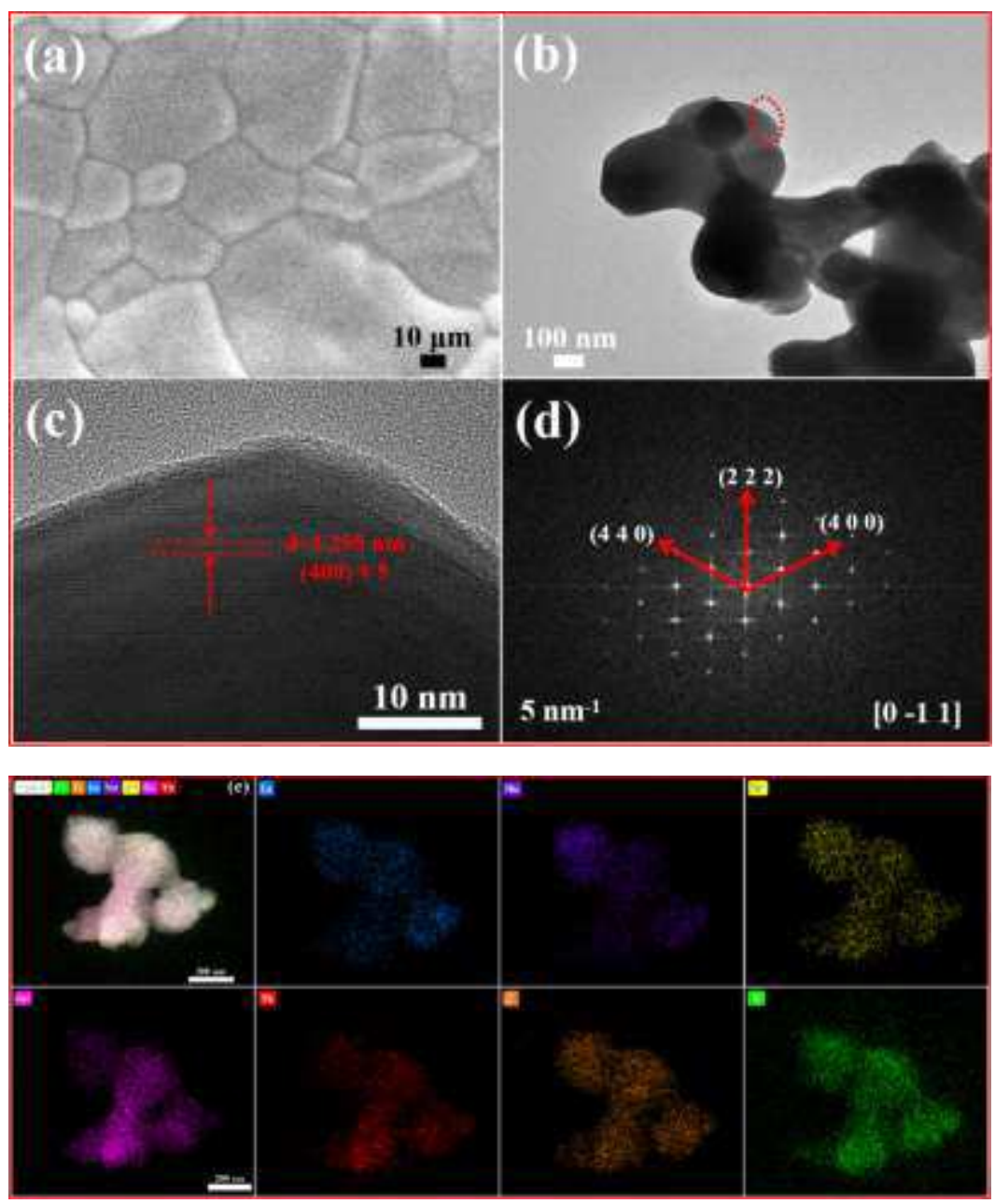

Fig. 3. (a) The microstructure of sintered $5 \mathrm{RE}_{2} \mathrm{Zr}_{2} \mathrm{O}_{7}$ ceramic bulk, (b) TEM image, (c) HRTEM image, (d) SAED pattern, and (e) TEM-EDS elemental mappings of the $5 \mathrm{RE}_{2} \mathrm{Zr}_{2} \mathrm{O}_{7}$ ceramic powder.

\section{Table 1}

The calculated lattice parameter and density, the experimental density and relative density of the ceramics after sintered at $1573 \mathrm{~K}$ for $3 \mathrm{~h}$.

\begin{tabular}{ccccc}
\hline Sample & Lattice parameter $(\AA)$ & $\rho\left(\mathrm{g} \cdot \mathrm{cm}^{-3}\right)$ & $\rho_{\mathrm{o}}\left(\mathrm{g} \cdot \mathrm{cm}^{-3}\right)$ & $\rho_{\mathrm{r}}(\%)$ \\
\hline $\mathrm{La}_{2} \mathrm{Zr}_{2} \mathrm{O}_{7}$ & 10.810 & 7.13 & 7.23 & 98.62 \\
$\mathrm{Yb}_{2} \mathrm{Zr}_{2} \mathrm{O}_{7}$ & 10.764 & 7.14 & 7.24 & 98.61 \\
$3 \mathrm{RE}_{2} \mathrm{Zr}_{2} \mathrm{O}_{7}$ & 10.642 & 7.11 & 7.22 & 98.47 \\
$5 \mathrm{RE}_{2} \mathrm{Zr}_{2} \mathrm{O}_{7}$ & 10.631 & 7.13 & 7.21 & 98.89 \\
\hline
\end{tabular}

Note: $\rho_{\mathrm{r}}=\rho / \rho_{o} ; \rho$ : experimental density; $\rho_{o}$ : theoretical density; $\rho_{\mathrm{r}}$ : relative density

Fig. 4(a) showed the XRD patterns of the as-prepared $5 \mathrm{RE}_{2} \mathrm{Zr}_{2} \mathrm{O}_{7}$ 
ceramic powders. No characteristic reflections of impurities were detected, demonstrated a pure face-centered cubic defective fluorite structure. Specifically, the XRD pattern peaks have different degrees of shift compared with those of each pure single counterparts due to the solid solution effect [34]. Fig. 4(b) showed the XRD patterns of the ceramic bulks. Obviously, the $5 \mathrm{RE}_{2} \mathrm{Zr}_{2} \mathrm{O}_{7}$ and $3 \mathrm{RE}_{2} \mathrm{Zr}_{2} \mathrm{O}_{7}$ ceramic bulks still obtained the characteristic diffraction peaks of defective fluorite structure without impurities. Notably, the peaks marked with black club for the $\mathrm{La}_{2} \mathrm{Zr}_{2} \mathrm{O}_{7}$ are characteristic superlattice diffraction peaks belonging to the pyrochlore structure [35].

Fig. 5(a-f) showed the ball-and-stick models of primitive cells obtained through first-principles calculations based on DFT. During the calculation process, the equilibrium lattice constants of $\mathrm{RE}_{2} \mathrm{Zr}_{2} \mathrm{O}_{7}(\mathrm{RE}=$ $\mathrm{La}, \mathrm{Nd}, \mathrm{Sm}, \mathrm{Gd}, \mathrm{Yb}$ ) primitive cell were optimized by using a $5 \times 5 \times 5$ Monkhorst-Pack k-point grid for Brillouin zone sampling. Therefore, the lattice constants $\left(\mathrm{a}=\mathrm{b}=\mathrm{c}, \alpha=\beta=\gamma=60^{\circ}\right)$ were presented to be $7.576 \AA, 7.510$ $\AA, 7.454 \AA, 7.401 \AA, 7.368 \AA, 7.483 \AA$ for $\mathrm{La}_{2} \mathrm{Zr}_{2} \mathrm{O}_{7}, \mathrm{Nd}_{2} \mathrm{Zr}_{2} \mathrm{O}_{7}$, $\mathrm{Sm}_{2} \mathrm{Zr}_{2} \mathrm{O}_{7}, \mathrm{Gd}_{2} \mathrm{Zr}_{2} \mathrm{O}_{7}, \mathrm{Yb}_{2} \mathrm{Zr}_{2} \mathrm{O}_{7}$ and $\mathrm{RE}_{2} \mathrm{Zr}_{2} \mathrm{O}_{7}$, respectively.

When neglecting the effect of lattice vibrational contribution, the $\square H_{m i x}$ and $\square S_{m i x}$ values were calculated to be $5.20 \mathrm{~kJ} \cdot \mathrm{mol}^{-1}$ and 1.298 $\mathrm{kJ} \cdot \mathrm{mol}^{-1}$ according to Equation 1 and Equation 2, respectively. Furthermore, the positive $\square H_{m i x}$ value indicated an endothermic reaction 
for the formation of $5 \mathrm{RE}_{2} \mathrm{Zr}_{2} \mathrm{O}_{7}$. Therefore, the mixing Gibbs free energy ( $\square G_{m i x}$ ) can be calculated according to Equation 3. The relationship between $\square G_{m i x}$ and temperature (Fig. 5(g)) indicated a possible stabilized solid solution.
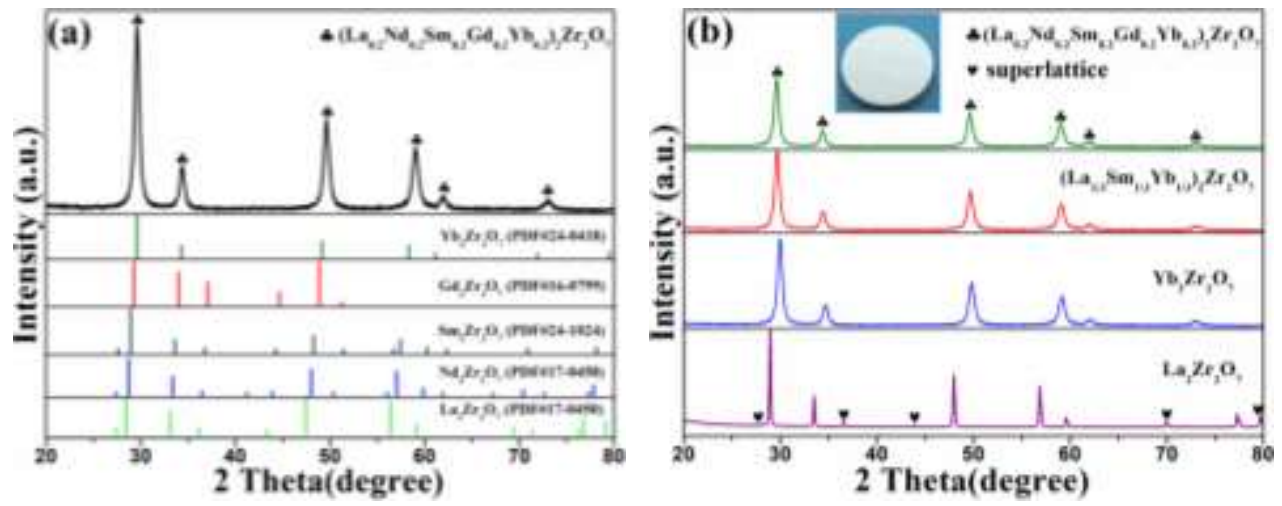

Fig. 4. $\mathrm{XRD}$ patterns of (a) $5 \mathrm{RE}_{2} \mathrm{Zr}_{2} \mathrm{O}_{7}$ ceramics powders, (b) $\mathrm{La}_{2} \mathrm{Zr}_{2} \mathrm{O}_{7}, \mathrm{Yb}_{2} \mathrm{Zr}_{2} \mathrm{O}_{7}$, $3 \mathrm{RE}_{2} \mathrm{Zr}_{2} \mathrm{O}_{7}$ and $5 \mathrm{RE}_{2} \mathrm{Zr}_{2} \mathrm{O}_{7}$ ceramics bulks.

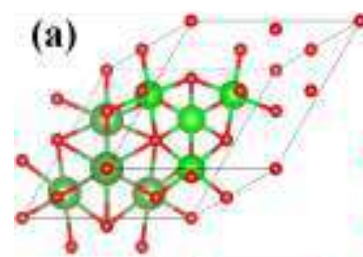

(d)
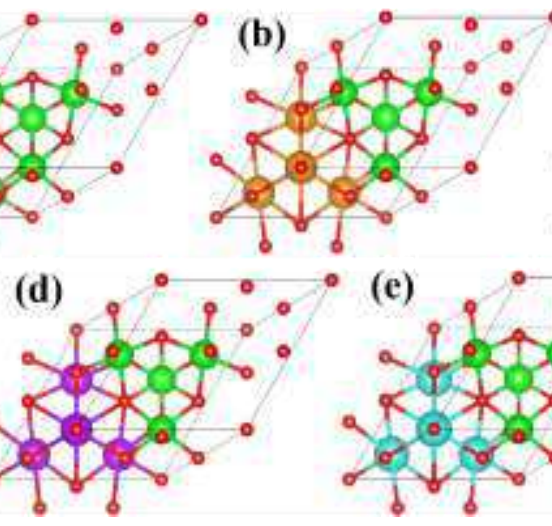

(e)

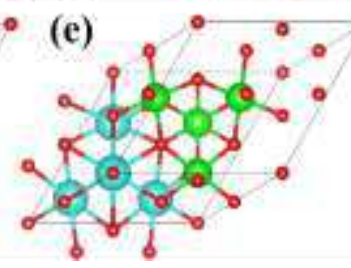

(f)

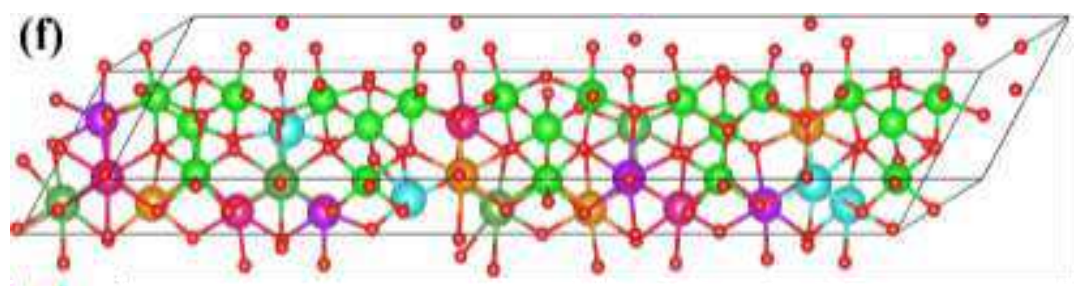

$\stackrel{\mathrm{g}}{\rightarrow} \quad \mathbf{O}$ atom $\mathrm{Zratom}$
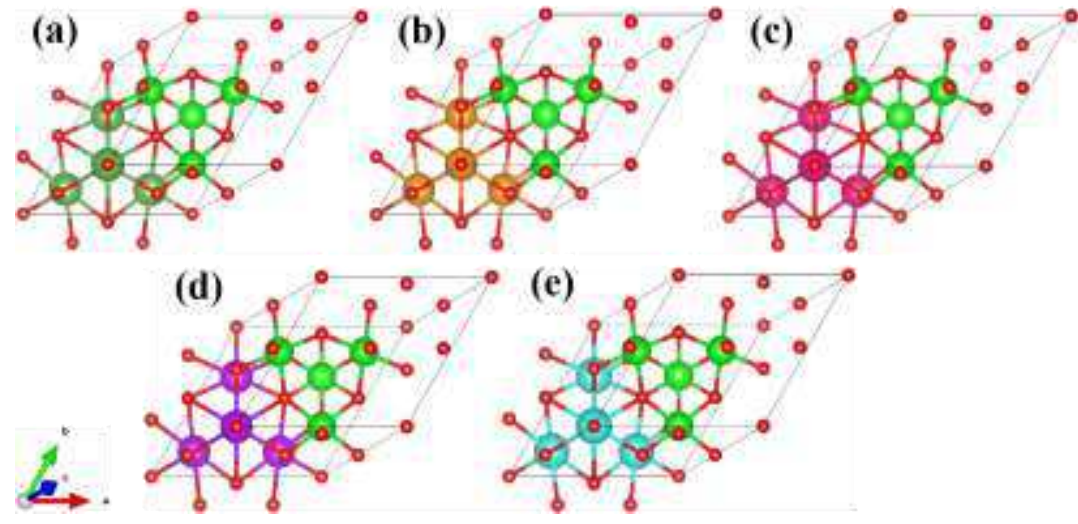


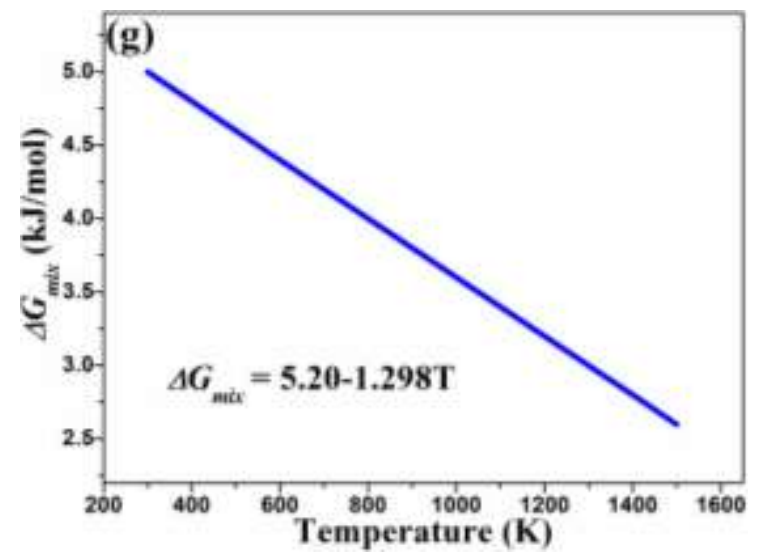

Fig. 5. Ball-and-stick models of primitive cells obtained through first-principles calculations based on density functional theory. (a) $\mathrm{La}_{2} \mathrm{Zr}_{2} \mathrm{O}_{7}$, (b) $\mathrm{Nd}_{2} \mathrm{Zr}_{2} \mathrm{O}_{7}$, (c) $\mathrm{Sm}_{2} \mathrm{Zr}_{2} \mathrm{O}_{7}$, (d) $\mathrm{Gd}_{2} \mathrm{Zr}_{2} \mathrm{O}_{7}$, (e) $\mathrm{Yb}_{2} \mathrm{Zr}_{2} \mathrm{O}_{7}$, (f) $5 \times 1 \times 1$ supercell for $\mathrm{RE}_{2} \mathrm{Zr}_{2} \mathrm{O}_{7}(\mathrm{RE}=\mathrm{La}$, $\mathrm{Nd}, \mathrm{Sm}, \mathrm{Gd}, \mathrm{Yb}) .(\mathrm{g})$ The Gibbs free energy of mixing $\left(\Delta G_{m i x}\right)$ of $5 \mathrm{RE}_{2} \mathrm{Zr}_{2} \mathrm{O}_{7}$ at different temperatures.

Fig. 6(a) presented the Raman spectra of the samples. There are six Raman active vibration modes associated with an $\mathrm{O}$ cation included in an ideal pyrochlore structure [36,37]:

$$
\Gamma(\text { Raman })=A_{1 g}+E_{g}+4 F_{2 g}
$$

Only one vibration mode $\left(\mathrm{F}_{2 \mathrm{~g}}\right)$ presented in an ideal fluorite structure. Obviously, the $\mathrm{Sm}_{2} \mathrm{Zr}_{2} \mathrm{O}_{7}\left(\mathrm{RE}_{2} \mathrm{Zr}_{2} \mathrm{O}_{7}\right)$ presented four typical vibration modes, indicating a pyrochlore structure. Furthermore, a broad and weak Raman peak can be found in sample $3 \mathrm{RE}_{2} \mathrm{Zr}_{2} \mathrm{O}_{7}$ and only one vibration mode $\left(F_{2 g}\right)$ was observed in sample $5 \mathrm{RE}_{2} \mathrm{Zr}_{2} \mathrm{O}_{7}$, which can be ascribed to the disordered structures from a high-entropy effect $[38,39]$.

As depicted in the FT-IR spectra (Fig. 6(b)), the peaks centered at $1187 \mathrm{~cm}^{-1}$ and $1108 \mathrm{~cm}^{-1}$ are ascribed to the stretching vibration of 
Zr-O-Zr bond [40]. While the peaks near $540 \mathrm{~cm}^{-1}$ and $3690 \mathrm{~cm}^{-1}$ are correspond to the vibration of $\mathrm{Zr}-\mathrm{O}$ stretching modes. A weak band centered at about $436 \mathrm{~cm}^{-1}$ associated with vibration of $\mathrm{O}-\mathrm{RE}-\mathrm{O}$ bending modes [41]. Specifically, peaks centered at $1380-1630 \mathrm{~cm}^{-1}$ are due to the water molecules in tested powders. However, no obvious characteristic peaks in sample $3 \mathrm{RE}_{2} \mathrm{Zr}_{2} \mathrm{O}_{7}$ and $5 \mathrm{RE}_{2} \mathrm{Zr}_{2} \mathrm{O}_{7}$ can be found because of the composition disorder caused by the high-entropy effect [42].

The TGA curve (Fig. 6(c)) presented a slight weight loss in a wide temperature range of $373 \mathrm{~K}-1473 \mathrm{~K}$, which can be ascribed to the evaporation of absorbed and bound water in the samples. The DSC curve indicated that the structure phase can keep stable up to $1473 \mathrm{~K}$ because no significant endothermic or exothermic peaks appeared.
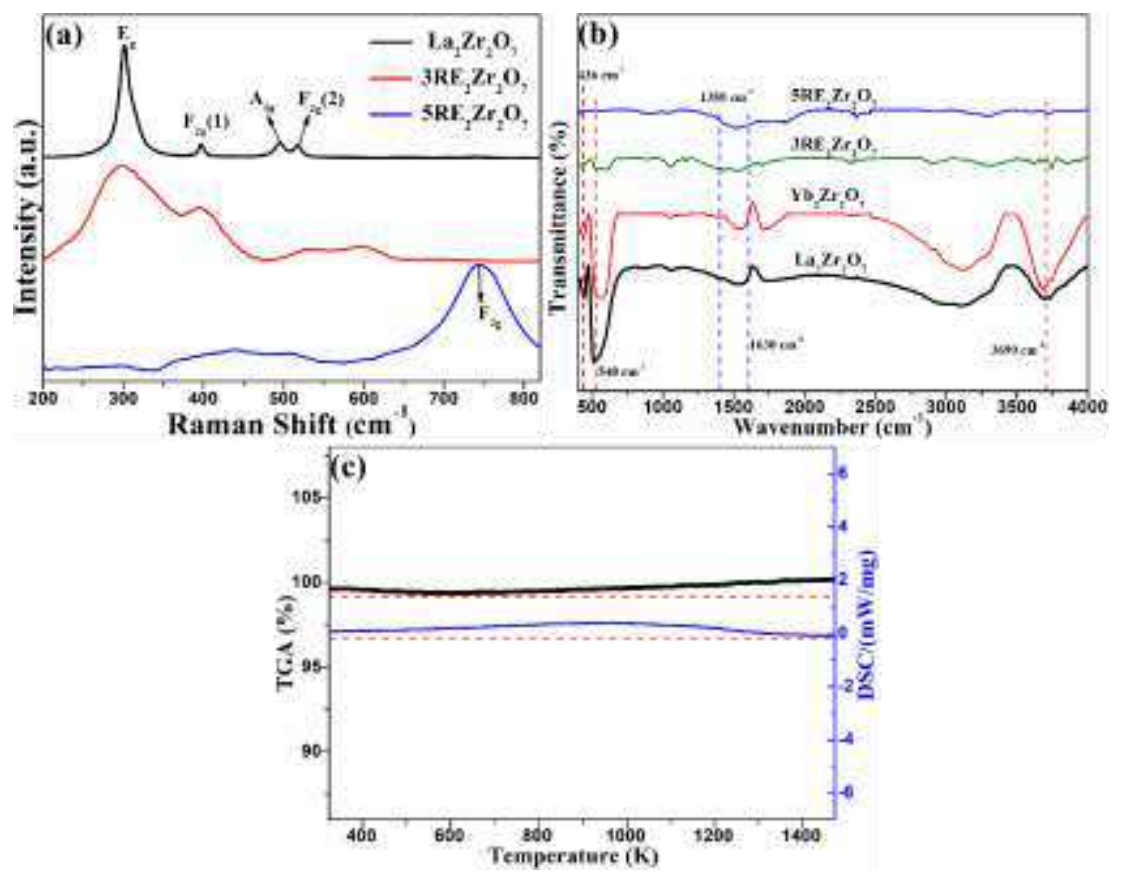

Fig. 6. Analysis of (a) Raman spectra, and (b) FT-IR spectra of the samples, (c) the TG and DSC curves of the $5 \mathrm{RE}_{2} \mathrm{Zr}_{2} \mathrm{O}_{7}$. 


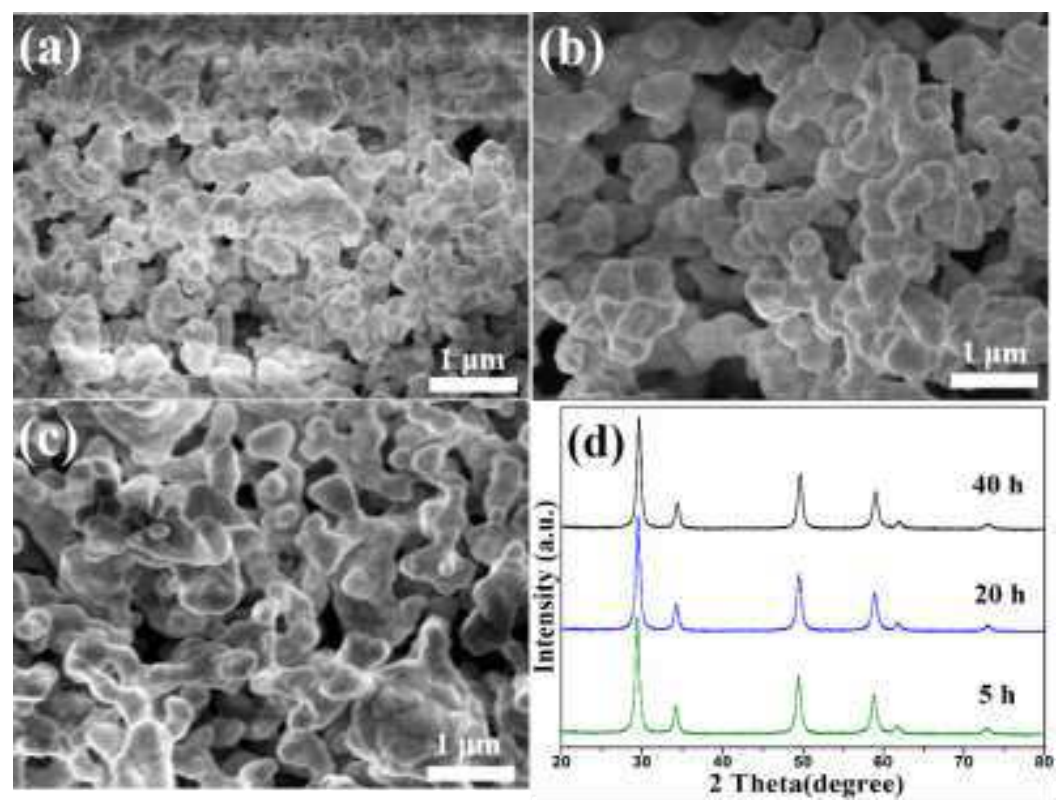

Fig. 7. The SEM images of $5 \mathrm{RE}_{2} \mathrm{Zr}_{2} \mathrm{O}_{7}$ after thermal-treated at $1573 \mathrm{~K}$ with different times: (a) $5 \mathrm{~h}$, (b) $20 \mathrm{~h}$, (c) $40 \mathrm{~h}$, and (d) the corresponding XRD patterns of the thermal-treated samples.

Generally speaking, the sintering resistance is an important criterion for TBCs [43]. The samples $5 \mathrm{RE}_{2} \mathrm{Zr}_{2} \mathrm{O}_{7}$ were aged at $1573 \mathrm{~K}$ for different times (seen Fig. 7(a-c)) to evaluate the high temperature stability. The coarsed grains indicated that the grain boundaries were thermally etched, while the grain size did not show apparent change due to the sluggish diffusion [24]. The corresponding XRD patterns (Fig. 7(d)) indicated that all the samples still obtained the defective fluorite-type structures with no phase decomposition or transformation detected. Because of the lattice expansion at high temperature, the XRD peaks moved towards lower angle with prolonged thermal aged times [13]. Hence, it can be conclude that the sample $5 \mathrm{RE}_{2} \mathrm{Zr}_{2} \mathrm{O}_{7}$ exhibited excellent sintering resistance and thermal stability at high temperature. 


\subsection{Thermophysical properties}

As shown in Fig. 8(a), the increased specific heat capacity values with increasing temperature were ascribed to the volumetric expansion and phonon excitation [44]. The experimental thermal diffusivity (Fig. 8(b)) showed a decrease tendency with increasing temperature (273-873 K) and then followed by a slight increase with prolonged temperature due to the thermal radiation effect at high temperature [13]. The crystal structure and lattice defects (pores and $\mathrm{O}$ vacancies) are the main reason for the decreased thermal diffusivity. The distortion of $\mathrm{O}$ vacancies can increase the distorted $\mathrm{O}$ sub-lattice, according to point defect scattering theory [45]. The thermal radiation effect can be neglected at high temperature, and the reciprocal thermal diffusivity $\left(\alpha^{-1}\right)$ should be proportional to the temperature [46]:

$$
\frac{1}{\alpha} \sim \frac{1}{l(w, T)} \sim\left(\frac{b n^{1 / 3} C}{\theta_{D}}\right) T+\left(D-\frac{C}{2}\right)
$$

where $\frac{1}{l(w, T)}$ is the phonon mean free path; $b, C$, and $D$ are constants; $n$ is the number of atoms in the primitive cell and $\theta_{D}$ is the Debye temperature. As shown in Fig. 8(c), the $\alpha^{-1}$ presented linear relationship (273-873 K) while decreased gradually with prolonged temperature due to the thermal radiation effect. As shown in Fig. 8(d), the sample $5 \mathrm{RE}_{2} \mathrm{Zr}_{2} \mathrm{O}_{7}$ presented lowest experimental thermal conductivity (0.9 $\mathrm{W} \cdot \mathrm{m}^{-1} \cdot \mathrm{K}^{-1}$ at $1273 \mathrm{~K}$ ) than that of $\mathrm{YSZ}$ and its counterparts in the entire 
temperature range. The linear relationship were fitted $(273-873 \mathrm{~K})$ and then extrapolated to $1273 \mathrm{~K}$, and the phonon thermal diffusivity and phonon thermal conductivity were obtained and showed in Fig. 8(e) and (f), respectively. The phonon-phonon scattering process can be enhanced with increased high temperature as well as the lattice distortion and quality difference caused by high-entropy effect, which can together decrease the mean free path and therefore decrease the thermal conductivity of the samples $[47,48]$.
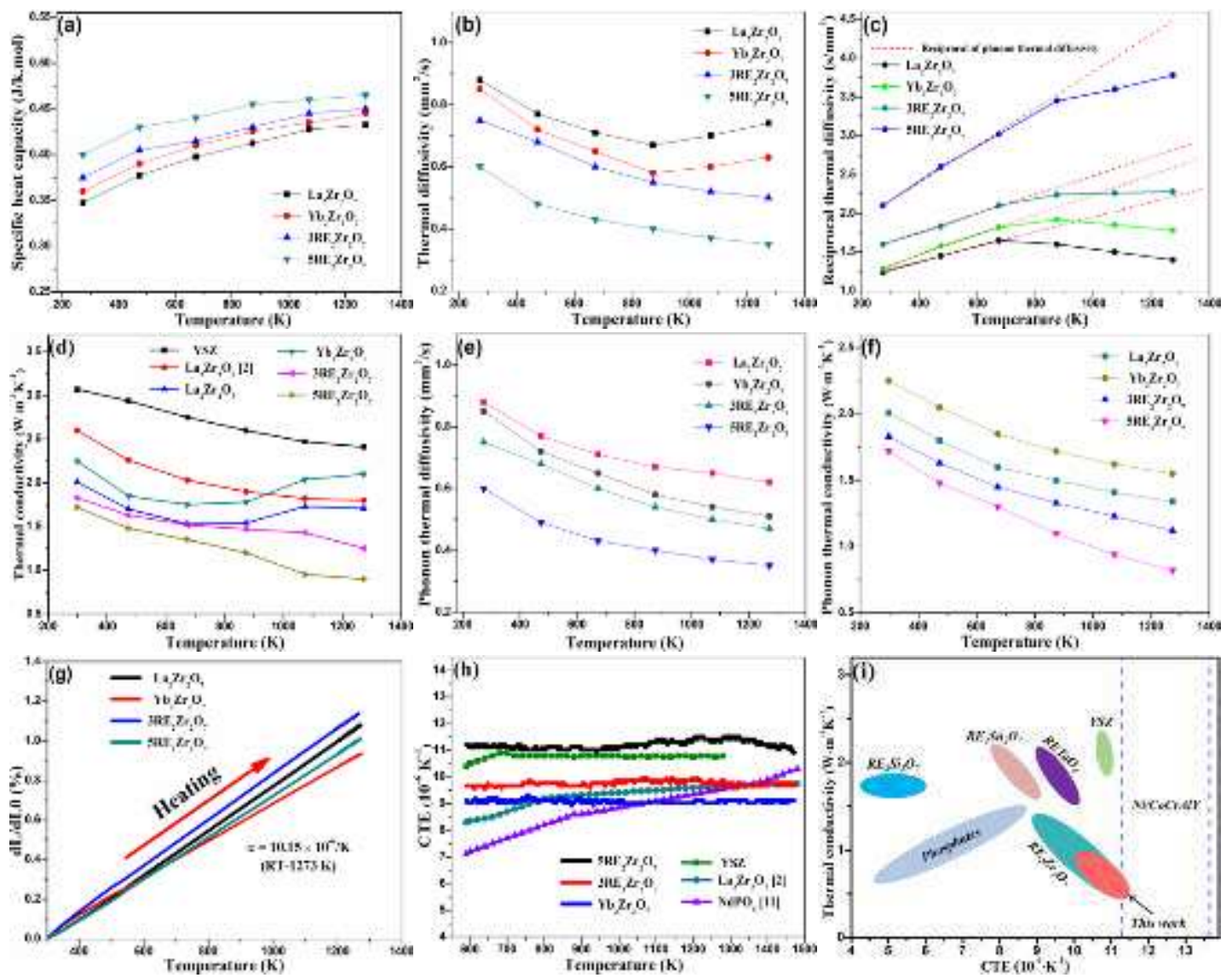

Fig. 8. Thermal physical properties of the samples: (a) specific heat capacity, (b) thermal diffusivity, (c) reciprocal of thermal diffusivity, (d) experimental thermal conductivity, (e) phonon thermal diffusivity, (f) phonon thermal conductivity, (g) linear thermal expansion curve, (h) thermal expansion coefficient, (i) thermal 
conductivity as a function of thermal expansion coefficient.

To further explore how the defects intrinsically affect the thermal conductivity, the following contents will be a good explanation. The proportional relationship between actual thermal conductivity $(k)$ and defect-free thermal conductivity $\left(k_{p}\right)$ are as follows [49]:

$$
\begin{aligned}
& \frac{k}{k_{p}}=\frac{\tan ^{-1} u}{u} \\
& u=\left(\frac{\pi^{2} \theta_{D} \Omega}{h v_{a}^{2}} k_{p} \Gamma\right)^{1 / 2}
\end{aligned}
$$

where $\Omega, \Gamma, \theta_{D}, h, N_{A}, \rho, M$, and $v_{a}$ represent the average atomic volume, phonon scattering coefficient, Debye temperature, Planck's constant, Avogadro's number, density, relative molecular mass, and average acoustic velocity, respectively. Obviously, the $\Gamma$ parameter plays a vital role in decreasing the actual thermal conductivity and it can be described as follows [50]:

$$
\Gamma=f_{i}\left\{\left(\frac{\Delta M_{i}}{M}\right)^{2}+2\left[6.4 \times \frac{1}{3} \gamma \frac{1+v}{1-v}\left(\frac{\Delta \delta_{i}}{\delta}\right)^{2}\right]\right\}
$$

where the subscript $i$ represents defect type, while the $M, \delta, f_{i}, \gamma$, and $v$ represent the average mass $\left(\Delta M_{i}=M-M_{i}\right)$, ionic radius at position $i\left(\Delta \delta_{i}=\right.$ $\delta$ - $\left.\delta_{i}\right)$, the defect concentration, the Grüneisen parameter, and the Poisson ratio, respectively. Therefore, the actual thermal conductivity is inversely proportional to the defect concentration $\left(f_{i}\right)$.

The thermal expansion rates (Fig. 8(g)) indicated that the slope of 
the curves were kept constant, indicating no phase transition occurs with increasing of temperature. The CTEs of $5 \mathrm{RE}_{2} \mathrm{Zr}_{2} \mathrm{O}_{7}$, as is shown in Fig. $8(\mathrm{~h})$, were $11.0 \times 10^{-6}-11.4 \times 10^{-6} \mathrm{~K}^{-1}(573-1473 \mathrm{~K})$, which are close to that of YSZ and larger than those of other samples, indicating its appropriateness to be used as TBCs. The relationship between CTEs and thermal conductivity of as-prepared $5 \mathrm{RE}_{2} \mathrm{Zr}_{2} \mathrm{O}_{7}$ and other works were listed in Fig. 8(i). Compared to YSZ and other TBCs, such as $\mathrm{RE}_{2} \mathrm{Si}_{2} \mathrm{O}_{7}$ [51], $\mathrm{RE}_{2} \mathrm{Zr}_{2} \mathrm{O}_{7}$ [52], $\mathrm{RE}_{2} \mathrm{Sn}_{2} \mathrm{O}_{7}$ [53], $\mathrm{REPO}_{4}$ [11] and $\mathrm{RETaO}_{4}$ [54], the as-prepared $5 \mathrm{RE}_{2} \mathrm{Zr}_{2} \mathrm{O}_{7}$ in this work performed lower thermal conductivity and higher CTEs which were close to reported metallic bond coating $\mathrm{Ni} / \mathrm{CoCrAlY}$ [55], indicating a bright application prospects in the fields of next generation TBCs.

\subsection{Mechanical properties}

The Young's modulus and Vickers hardness (measured by Vickers indentation method) were shown in Fig. 9(a). It can been seen that the $5 \mathrm{RE}_{2} \mathrm{Zr}_{2} \mathrm{O}_{7}$ ceramic showed improved Young's modulus (262 GPa) and Vickers hardness (11.78 GPa) compared to its counterparts. Fig. 9(b) depicted the fracture toughness calculated based on the Vickers hardness and Young's modulus (the $\mathrm{C}$ value was seen in Fig. 9(c)). Notably, the fracture toughness of the $5 \mathrm{RE}_{2} \mathrm{Zr}_{2} \mathrm{O}_{7}$ ceramic was as high as $2.7 \mathrm{MPa} \cdot \mathrm{m}^{1 / 2}$, which is higher than that of the $\operatorname{YSZ}\left(2.5 \mathrm{MPa} \cdot \mathrm{m}^{1 / 2}\right)[56]$ and nearly twice than that of the reported $\mathrm{La}_{2} \mathrm{Zr}_{2} \mathrm{O}_{7}$ [2]. 

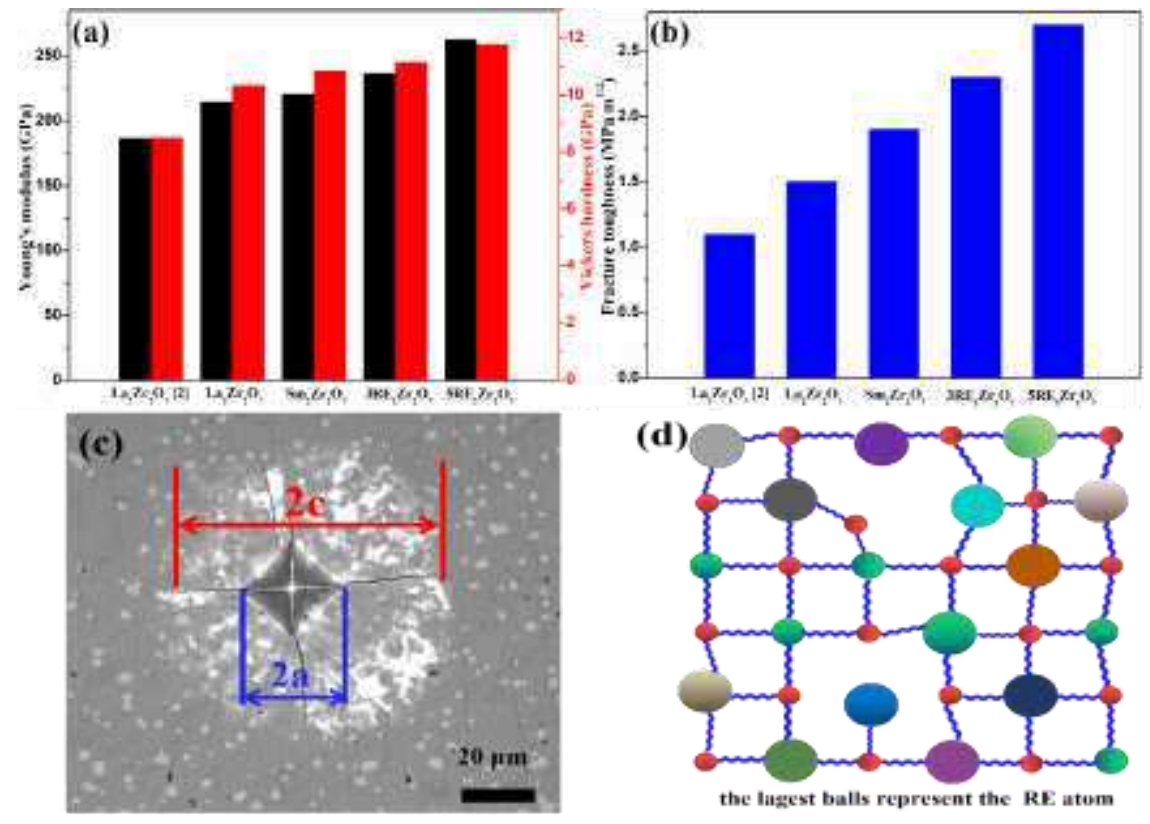

Fig. 9. (a) The Young's modulus and Vickers hardness and (b) fracture toughness of the samples, (c) typical photograph of nano-indentation morphology of the $5 \mathrm{RE}_{2} \mathrm{Zr}_{2} \mathrm{O}_{7}$ ceramics under a $100 \mathrm{~g}$ indentation load, (d) schematic diagram of lattice framework of $5 \mathrm{RE}_{2} \mathrm{Zr}_{2} \mathrm{O}_{7}$.

The schematic diagram of lattice framework (Fig. 9(d)) of $5 \mathrm{RE}_{2} \mathrm{Zr}_{2} \mathrm{O}_{7}$ presented the randomly occupied $\mathrm{RE}$ cations and different size between $\mathrm{Zr}$ and $\mathrm{RE}$. This kind of outstanding disordered composition configuration performed the previously mentioned cocktail effect $[57,58]$, which includes mass difference, chemical bonding deviation, and local lattice distortion, which together affect the mechanical properties of the sample $5 \mathrm{RE}_{2} \mathrm{Zr}_{2} \mathrm{O}_{7}$. Furthermore, a good damage tolerance of the ceramics can be characterized through brittleness index (M) [59]:

$$
M=\frac{H_{V}}{K_{I C}}
$$

Therefore, the $\mathrm{M}$ value of the sample $5 \mathrm{RE}_{2} \mathrm{Zr}_{2} \mathrm{O}_{7}$ is calculated to be 4.36 $\mu \mathrm{m}^{-1 / 2}$, which is lower than that of reported YSZ $\left(7 \mu \mathrm{m}^{-1 / 2}\right)$ [60], indicating 
that the as-prepared sample $5 \mathrm{RE}_{2} \mathrm{Zr}_{2} \mathrm{O}_{7}$ ceramic has a better damage tolerance.

\section{Conclusions}

Herein, by using a new high-speed grinding strategy combined with typical solid-state reaction method, a new kind of $5 \mathrm{RE}_{2} \mathrm{Zr}_{2} \mathrm{O}_{7}$ ceramics were successfully fabricated and systematically investigated. The XRD patterns and EDS mappings indicated that all the $5 \mathrm{RE}_{2} \mathrm{Zr}_{2} \mathrm{O}_{7}$ ceramics formed a homogeneous single defect fluorite structure without any elemental segregation. The Gibbs free energy of mixing calculated through first-principles calculations showed that the synthesis of the $5 \mathrm{RE}_{2} \mathrm{Zr}_{2} \mathrm{O}_{7}$ ceramics is energetically favorable. In addition, the sample $5 \mathrm{RE}_{2} \mathrm{Zr}_{2} \mathrm{O}_{7}$ ceramics exhibited good high-temperature phase stability, excellent thermophysical properties (low thermal conductivities and high CTEs), and ideal mechanical properties including larger Young's modulus and fracture toughness. The excellent integrated properties of the sample $5 \mathrm{RE}_{2} \mathrm{Zr}_{2} \mathrm{O}_{7}$ ceramics suggest that they are potential candidates for new type of next generation TBCs.

\section{Declaration of Competing Interest}

The authors declare no conflict of interest.

\section{Acknowledgements}

This work is supported by the National Science and Technology Major 
Project (2017-VI-0020-0093), National Natural Science Foundation of

China (Nos.12090031 and 11602125), and National Key Research and Development of China (2018YFA0702804).

\section{References}

[1] R. Vassen, X.Q. Cao, D. Stöver, et al. Zirconates as New Materials for Thermal Barrier Coatings. J Am Ceram Soc 2000,83:2023-2028.

[2] J. Wu, X.Z. Wei, M.I. Osendi, et al. "Low-Thermal-Conductivity Rare-Earth Zirconates for Potential Thermal-Barrier-Coating Applications." J Am Ceram Soc 2002,85:3031-3035.

[3] Z.F. Zhao, H. Chen, Y.C. Zhou, et al. High entropy defective fluorite structured rare-earth niobates and tantalates for thermal barrier applications. J Adv Ceram 2020,9(3):303-311.

[4] N.P. Padture, M. Gell, E.H. Jordan. Thermal barrier coatings for gas-turbine engine applications. Science 2002,296:280-284.

[5] D.R. Clarke, S.R. Phillpot. Thermal barrier coating materials. Mater Today 2005,8:22-29.

[6] R. Vaßen, M.O. Jarligo, D. Stöver, et al. Overview on advanced thermal barrier coatings. Surf Coat Technol 2010,205:938-942.

[7] B. Liu, Y.C. Liu, Y.C. Zhou, et al. Advances on strategies for searching for next generation thermal barrier coating materials. J Mater Sci Technol 2019,35:833-851.

[8] D.R. Clarke, M. Oechsner, N.P. Padture. Thermal-barrier coatings for more efficient gas-turbine engines. MRS Bull 2012,37:891-898.

[9] Y.C. Zhou, H.M. Xiang, Z.H. Feng. Theoretical Investigation on Mechanical and Thermal Properties of a Promising Thermal Barrier Material: $\mathrm{Yb}_{3} \mathrm{Al}_{5} \mathrm{O}_{12}$. J Mater Sci Technol 2014,30:631-638.

[10] J.A. Curran, H. Kalkanc, T.W. Clyne, et al. Mullite-rich plasma electrolytic oxide coatings for thermal barrier applications. Surf Coat Tech 2007,201(21): 8683-8687.

[11] A. Joulia, M. Vardelle, S. Rossignol. Synthesis and thermal stability of $\operatorname{Re}_{2} \mathrm{Zr}_{2} \mathrm{O}_{7}$, 
( $\mathrm{Re}=\mathrm{La}, \mathrm{Gd})$ and $\mathrm{La}_{2}\left(\mathrm{Zr}_{1-\mathrm{x}} \mathrm{Ce}_{\mathrm{x}}\right)_{2} \mathrm{O}_{7-\delta}$ compounds under reducing and oxidant atmospheres for thermal barrier coatings. J Eur Ceram Soc 2013,33:2633-2644.

[12] A. Du, C. Wan, P. Wei, et al. Thermal Conductivity of Monazite-Type REPO (RE=La, Ce, Nd, Sm, Eu, Gd). J Am Ceram Soc 2010,92(11):2687-2692.

[13] H.M. Xiang, Z.H. Feng, Y.C. Zhou, et al. Crystal structure, mechanical and thermal properties of $\mathrm{Yb}_{4} \mathrm{Al}_{2} \mathrm{O}_{9}$ : a combination of experimental and theoretical investigations. J Eur Ceram Soc 2017,37:2491-2499.

[14] K. Ren, Q.K. Wang, Y.G. Wang, et al. Multicomponent high- entropy zirconates with comprehensive properties for advanced thermal barrier coating. Scripta Mater 2020,178:382-386.

[15] A.J. Wright, Q.Y. Wang, J. Luo, et al. Size disorder as a descriptor for predicting reduced thermal conductivity in medium- and high-entropy pyrochlore oxides. Scripta Mater 2020,181:76-81.

[16] X.Q. Cao, R. Vassen, D. Stöver, et al. New double-ceramic-layer thermal barrier coatings based on zirconia-rare earth composite oxides. J Eur Ceram Soc 2006, 26(3):247-251.

[17] M.A. Subramanian, G. Aravamudan, G.V. Subba Rao. Oxide pyrochlores-A review. Prog Solid State Chem 1983,15:55-143.

[18] W. Ma, D. Mack, D. Stöver, et al. $\mathrm{Yb}_{2} \mathrm{O}_{3}$ and $\mathrm{Gd}_{2} \mathrm{O}_{3}$ doped strontium zirconate for thermal barrier coatings. J Eur Ceram Soc 2008,28(16):3071-3081.

[19] Z.H. Xu, L.M. He, X.Q. Cao, et al. Double ceramic-layer thermal barrier coatings of $\mathrm{La}_{2} \mathrm{Zr}_{2} \mathrm{O}_{7} / \mathrm{YSZ}$ deposited by electron beam-physical vapor deposition. $J$ Alloys Compd 2009,473(1):509-515.

[20] X.Q. Cao, J. Li, D. Stöver, et al. $\mathrm{La}_{2}\left(\mathrm{Zr}_{0.7} \mathrm{Ce}_{0.3}\right)_{2} \mathrm{O}_{7}-\mathrm{A}$ new oxide ceramic material with high sintering-resistance. Mater Lett 2008,62(17-18):2667-2669.

[21] R.Z. Zhang, M.J. Reece. Review of high entropy ceramics: design, synthesis, structure and properties. J Mater Chem A 2019,7:22148-22162.

[22] J.T. Zhu, X.Y. Meng, F. Gao, et al. Ultra-low thermal conductivity and enhanced mechanical properties of high-entropy rare earth niobates $\left(\mathrm{RE}_{3} \mathrm{NbO}_{7}, \mathrm{Re}=\mathrm{Dy}, \mathrm{Y}, \mathrm{Ho}\right.$, Er, Yb). J Eur Ceram Soc 2021,1(41):1052-1057. 
[23] Z.F. Zhao, H.M. Xiang, Y.C. Zhou, et al. $\left(\mathrm{La}_{0.2} \mathrm{Ce}_{0.2} \mathrm{Nd}_{0.2} \mathrm{Sm}_{0.2} \mathrm{Eu}_{0.2}\right)_{2} \mathrm{Zr}_{2} \mathrm{O}_{7}$ : A novel high-entropy ceramic with low thermal conductivity and sluggish grain growth rate. J Mat Sci Tech 2019,35(11):2647-2651.

[24] L. Zhou, F. Li, J.X. Liu. High-Entropy Thermal Barrier Coating of Rare-Earth Zirconate: A Case Study on $\left(\mathrm{La}_{0.2} \mathrm{Nd}_{0.2} \mathrm{Sm}_{0.2} \mathrm{Eu}_{0.2} \mathrm{Gd}_{0.2}\right)_{2} \mathrm{Zr}_{2} \mathrm{O}_{7}$ Prepared by Atmospheric Plasma Spraying. J Eur Ceram Soc 2020,40(15):5731-5739.

[25] F. Li, J.X. Liu, G.J. Zhang, et al. High-entropy pyrochlores with low thermal conductivity for thermal barrier coating materials. J Adv Cera 2019,8:576-582.

[26] M.D. Segall, P.J.D. Lindan, M.C. Payne, et al. First-principles simulation: ideas, illustrations and the CASTEP code. J Phys-Condens Mat 2002,14:2717-2744.

[27] J.P. Perdew, K. Burke, M. Ernzerhof. Generalized gradient approximation made simple. Phys Rev Lett 1998,77(18):3865-3868.

[28] B. Miracle, O.N. Senkov. A critical review of high entropy alloys and related concepts. Acta Mater 2017,122:448-511.

[29] J. Leitner, P. Vonka, P. Svoboda, et al. Application of Neumann-Kopp rule for the estimation of heat capacity of mixed oxides. Thermochimi Acta 2010,497:7-13.

[30] A.J. Burggraaf, T.V. Dijk, M.J. Verkerk, et al. Structure and Conductivity of Pyrochlore and Fluorite Type Solid Solutions. Solid State Ionics 1981,5:519-522.

[31] F. Vayer, C. Decorse, N. Dragoe, et al. New entropy-stabilized oxide with pyrochlore structure: $\mathrm{Dy}_{2}\left(\mathrm{Ti}_{0.2} \mathrm{Zr}_{0.2} \mathrm{Hf}_{0.2} \mathrm{Ge}_{0.2} \mathrm{Sn}_{0.2}\right)_{2} \mathrm{O}_{7}$. J Alloy Compd 2021,41: 60806086.

[32] Y. Liu, R.L. Withers, L. Norén. The Pyrochlore to 'Defect Fluorite' Transition in the $\mathrm{Y}_{2}(\text { ZryTily })_{2} \mathrm{O}_{7}$ System and Its Underlying Crystal Chemistry. J Solid State Chem 2004,117:4404-4412.

[33] J.T. Zhu, X.Y. Meng, F. Gao, et al. Dual-phase rare-earth-zirconate high-entropy ceramics with glass-like thermal conductivity. J Eur Ceram Soc 2021,41:2861-2869. [34] J. Feng, B. Xiao, W. Pan, et al. Electronic structure, mechanical properties and thermal conductivity of $\mathrm{Ln}_{2} \mathrm{Zr}_{2} \mathrm{O}_{7}(\mathrm{Ln}=\mathrm{La}, \mathrm{Pr}, \mathrm{Nd}, \mathrm{Sm}, \mathrm{Eu}$ and $\mathrm{Gd})$ pyrochlore. Acta Mater 2011,59:1742-1760. 
[35] Z. Teng, L.N. Zhu, H.B. Zhang, et al. Synthesis and structures of high-entropy pyrochlore oxides. J Eur Ceram Soc 2019,40:1639-1643.

[36] C.L. Wan, Z.X. Qu, W. Pan, et al. Order-Disorder Transition and Unconventional Thermal Conductivities of the $\left(\mathrm{Sm}_{1-\mathrm{x}} \mathrm{Yb}_{\mathrm{x}}\right)_{2} \mathrm{Zr}_{2} \mathrm{O}_{7}$ Series. $J$ Am Ceram Soc 2011,94:592-596.

[37] B.D. Begg, N.J. Hess, W.J. Weber, et al. Heavy-Ion Irradiation Effects in $\mathrm{Gd}_{2}\left(\mathrm{Ti}_{2-\mathrm{x}} \mathrm{Zr}_{\mathrm{x}}\right) \mathrm{O}_{7}$ Pyrochlores. J Nucl Mater 2001,289:188-193.

[38] M. Glerup, O.F. Nielsen, F.W. Poulsen, et al. The Structural Transformation from the Pyrochlore Structure, $\mathrm{A}_{2} \mathrm{~B}_{2} \mathrm{O}_{7}$, to the Fluorite Structure, $\mathrm{AO}_{2}$, Studied by Raman Spectroscopy and Defect Chemistry Modeling. J Solid State Chem 2001,160:25-32.

[39] P. Blanchard, S. Liu, A. Tadich, et al. Investigating the Local Structure of Lanthanoid Hafnates $\mathrm{Ln}_{2} \mathrm{Hf}_{2} \mathrm{O}_{7}$ via Diffraction and Spectroscopy. J Phys Chem C 2013,117:2266-2273.

[40] M. Diaz, C. Pecharroman, S.M. Castano, et al. Synthesis, thermal evolution, and luminescence properties of yttrium disilicate host matrix. Chem Mater 2005,17:17741782.

[41] L. Zhou, Z.Y. Huang, T.C. Lu, et al. Thermal-Driven Fluorit-Pyrochlor-Fluorite Phase Transitions of $\mathrm{Gd}_{2} \mathrm{Zr}_{2} \mathrm{O}_{7}$ Ceramics Probed in Large Range of Sintering Temperature. Metall Mater Trans A 2016,47:623-630.

[42] L. Kong, I. Karatchevtseva, G. Triani, et al. $\mathrm{Gd}_{2} \mathrm{Zr}_{2} \mathrm{O}_{7}$ and $\mathrm{Nd}_{2} \mathrm{Zr}_{2} \mathrm{O}_{7}$ pyrochlore prepared by aqueous chemical synthesis. J Eur Ceram Soc 2013,33:3273-3285.

[43] P. Wei, S.R. Phillpot, Z. Qu, et al. Low thermal conductivity oxides. MRS Bull 2012,37:917-922.

[44] M. Zhao, X.R. Ren, W. Pan, et al. Low thermal conductivity of rare-earth zirconate-stannate solid solutions $\left(\mathrm{Yb}_{2} \mathrm{Zr}_{2} \mathrm{O}_{7}\right)_{1-\mathrm{x}}\left(\mathrm{Ln}_{2} \mathrm{Sn}_{2} \mathrm{O}_{7}\right)_{\mathrm{x}}(\mathrm{Ln}=\mathrm{Nd}, \mathrm{Sm}) . J \mathrm{Am}$ Ceram Soc 2016,99:293-299. 
[45] Sood A, Cheaito R, Kwon H, et al. Direct visualization of thermal conductivity suppression due to enhanced phonon scattering near individual grain boundaries. Nano Lett 2018,18:3466-3472.

[46] F.F. Zhou, Y. Wang, C.H. Wang, et al. Thermal cycling behavior of nanostructured $8 \mathrm{YSZ}, \mathrm{SZ} / 8 \mathrm{YSZ}$ and $8 \mathrm{CSZ} / 8 \mathrm{YSZ}$ thermal barrier coatings fabricated by atmospheric plasma spraying. Ceram Int 2017,43(5):4102-4111.

[47] L. Chen, P. Wu, J. Feng, et al. Potential thermal barrier coating materials: $\mathrm{RE}_{3} \mathrm{NbO}_{7}(\mathrm{RE}=\mathrm{La}, \mathrm{Nd}, \mathrm{Sm}, \mathrm{Eu}, \mathrm{Gd}, \mathrm{Dy})$ ceramics. $J$ Am Ceram Soc 2018,101:45034508.

[48] J.L. Braun, C.M. Rost, P.E. Hopkins, et al. Charge-induced disorder controls the thermal conductivity of entropy-stabilized oxides. Adv Mater 2018,30:1805004.

[49] J. Callaway, H.C.V. Baeyer. Effect of point imperfections on lattice thermal conductivity. Phys Rev 1960,120:1149-1154.

[50] C.L. Wan, W. Pan, M.H. Fang, et al. Effect of point defects on the thermal transport properties of $\left(\mathrm{La}_{\mathrm{x}} \mathrm{Gd}_{1-\mathrm{x}}\right)_{2} \mathrm{Zr}_{2} \mathrm{O}_{7}$ : experiment and theoretical model. Phys Rev B 2006,74:144109.

[51] Z. Tian, L. Zheng, J. Wang, et al. Exploration of the low thermal conductivities of $\gamma-\mathrm{Y}_{2} \mathrm{Si}_{2} \mathrm{O}_{7}, \beta-\mathrm{Y}_{2} \mathrm{Si}_{2} \mathrm{O}_{7}, \beta-\mathrm{Yb}_{2} \mathrm{Si}_{2} \mathrm{O}_{7}$, and $\beta-\mathrm{Lu}_{2} \mathrm{Si}_{2} \mathrm{O}_{7}$ as novel environmental barrier coating candidates. J Eur Ceram Soc 2016,36(11):2813-2823.

[52] L. Zhou, X. Cao, G.J. Zhang, et al. Highentropy thermal barrier coating of rare-earth zirconate: a case study on $\left(\mathrm{La}_{0.2} \mathrm{Nd}_{0.2} \mathrm{Sm}_{0.2} \mathrm{Eu}_{0.2} \mathrm{Gd}_{0.2}\right)_{2} \mathrm{Zr}_{2} \mathrm{O}_{7}$ prepared by atmospheric plasma spraying. J Eur Ceram Soc 2020,40(15):5731-5739.

[53] Z. Qu, C. Wan, W. Pan. Thermophysical properties of rare-earth stannates: Effect of pyrochlore structure. Acta Mate 2012,60:2939-2949.

[54] L. Chen, M. Hu, J. Feng, et al. Thermal expansion performance and intrinsic lattice thermal conductivity of ferroelastic $\mathrm{RETaO}_{4}$ ceramics. J Am Ceram Soc 2019,102:4809-4821. 
[55] L. Xu, H. Wang, H.F. Gao, et al. A new class of high-entropy fluorite oxides with tunable expansion coefficients, low thermal conductivity and exceptional sintering resistance. J Eur Ceram Soc 2021,41:6670-6676.

[56] M. Kibsey, X. Huang, Q. Yang, et al. Mechanical properties of titania-doped yttria stabilized zirconia (TiYSZ) for use as thermal barrier coating (TBC). J Eng Gas Turb Power 2011,133(12):122101.

[57] Z.Z. Li, S.T. Zhao, M.A. Meyers, et al. Mechanical properties of high-entropy alloys with emphasis on face-centered cubic alloys. Prog Mate Science 2019,102:296-345.

[58] J.Y. He, W.H. Liu, Z.P. Lu, et al. Effects of Al addition on structural evolution and tensile properties of the feconicrmn high-entropy alloy system. Acta Mate 2014,62:105-113.

[59] A.R. Boccaccini. Machinability and brittleness of glass-ceramics. J Mater Process Tech 1997,65:302-304.

[60] NIST material properties database in web of the American Ceramics Society. 